\title{
Analisis Pengaruh Panjang Gelombang Cahaya Terhadap Keluaran Panel Surya Tipe Polycrystalline
}

\author{
Ni Luh Putu Mustia Sridewi $i^{1)^{*}}$, Hery Suyanto ${ }^{2)}$, I Gusti Bagus Wijaya Kusuma ${ }^{3)}$ \\ ${ }^{1,2)}$ Jurusan Fisika, Fakultas Matematika dan Ilmu Pengetahuan Alam, Universitas Udayana \\ 3) Jurusan Teknik Mesin, Fakultas Teknik, Universitas Udayana \\ Kampus Bukit Jimbaran, Bali 80362 \\ Email: mustiasridewi01@gmail.com, hery@unud.ac.id, wijaya.kusuma88@yahoo.com
}

doi: https://doi.org/10.24843/METTEK.2018.v04.i02.p03

\begin{abstract}
Abstrak
Telah dilakukan penelitian tentang pengaruh panjang gelombang cahaya terhadap daya keluaran pada panel surya tipe policrystalline. Penelitian ini bertujuan untuk mengetahui pengaruh panjang gelombang cahaya terhadap daya keluaran pada panel surya. Pengukuran dilakukan dengan mengukur tegangan dan arus pada panel surya menggunakan cahaya lampu berwarna merah, kuning, hijau dan biru dengan panjang gelombang masing-masing $706 \mathrm{~nm}, 662 \mathrm{~nm}, 538 \mathrm{~nm}$ dan $496 \mathrm{~nm}$. Data Menunjukan bahwa warna merah yang mempunyai panjang gelombang lebih besar, menghasilkan daya keluaran yang lebih besar dibandingkan dengan warna kuning, hijau dan biru.
\end{abstract}

Kata kunci: Panjang gelombang, Daya keluaran, Panel surya, Policrystalline, Cahaya

\begin{abstract}
Research on the effect of light wavelengths on the power output of solar panels polycrystalline type. This study aims to determine the effect of light wavelength on the power output of solar panels. Measurements were performed by measuring voltage and current on solar panels using red, yellow, green and blue lights with their respective wavelengths on red, yellow, green and blue lights with a wavelength of $706 \mathrm{~nm}, 662 \mathrm{~nm}, 538 \mathrm{~nm}$, and $496 \mathrm{~nm}$ respectively. Data shows that the red color has a larger wavelength, resulting in greater output power compared to yellow, green and blue.
\end{abstract}

Keywords: Wavelength, Power output, Solar panel, Polycrystalline, lights.

\section{PENDAHULUAN}

Kemajuan teknologi saat ini berpengaruh terhadap tingginya kebutuhan energi listrik. Salah satu energi alternative yang dapat dimanfaatkan untuk menghasilkan energi listrik adalah energi matahari. Energi dari cahaya matahari merupakan sumber energi yang paling menjanjikan karena bersifat berkelanjutan (sustainable). Panel surya merupakan suatu perangkat yang memiliki kemampuan mengubah energi cahaya matahari menjadi energi listrik dengan mengikuti prinsip photovoltaic, yakni terbentuknya energi dari cahaya (foton) pada panjang gelombang tertentu agar dapat mengeksitasi sebagian elektron pada suatu material ke pita energi (konduksi) ${ }^{[1]}$. Jenis panel surya ada berbagai macam diantaranya yaitu monocrystalline dan polycrystalline. Panel surya monocrystalline merupakan panel surya dengan susunan kristal tunggal dan efisiensi berkisar 14\%-17\% sedangkan panel surya polycrystalline merupakan panel surya dengan susunan kristal acak dengan efisiensi lebih kecil yaitu berkisar $12 \%-14 \%{ }^{[2]}$ Daya keluaran panel surya berpengaruh terhadap intensitas dan panjang gelombang radiasi cahaya namun dinyatakan bahwa pada terik matahari yang

Penulis korespondensi, HP: 082147011637

Email: mustiasridewi01@gmail.com 
tinggi, daya keluaran panel surya menurun. Oleh karena itu, maka dilakukan penelitian mengenai analisis pengaruh panjang gelombang cahaya terhadap daya keluaran pada panel surya.

Semikonduktor merupakan bahan dengan konduktivitas listrik yang berada diantara isolator dan konduktor. Sebuah semikonduktor akan bersifat sebagai isolator pada temperatur yang sangat rendah karena pita konduksi semikonduktor tidak terisi oleh elektron. Menurut teori pita energi, pada $T=0 \mathrm{~K}$ pita valensi semikonduktor terisi penuh elektron, sedangkan pita konduksi kosong. Kedua pita tersebut dipisahkan oleh celah energi, yakni dalam rentang 0,18 - 3,7 eV. Pada suhu kamar Si dan Ge masing-masing memiliki celah energi 1,11 eV dan $0,66 \mathrm{eV}^{[3]}$. Bila mendapat cukup energi, misalnya berasal dari energi panas, elektron dapat melepaskan diri dari ikatan kovalen dan tereksitasi menyebrangi celah energi. ${ }^{[3]}$ Hubungan dasar dari elektronik semikonduktor merupakan sambungan $\mathrm{p}-\mathrm{n}$ ( $\mathrm{p}-\mathrm{n}$ junction). Sambungan $\mathrm{p}-$ $\mathrm{n}$ tidak bisa dibentuk hanya dengan menghubungkan semikonduktor tipe $\mathrm{p}$ dan tipe $\mathrm{n}$. Sambungan p-n akan didapatkan jika sebagian dari substrat kristal menjadi tipe-n dengan menambah donor dan bagian yang lain menjadi tipe-p dengan menambah aseptor. ${ }^{[4,5]}$

Sebuah panel surya bekerja dengan menggunakan efek photovoltaic. Efek ini dapat timbul terutama pada semikonduktor yang memiliki konduktivitas menengah dikarenakan sifat elektron di dalam material yang terpisah dalam pita-pita energi tertentu yang disebut pita konduksi dan pita valensi. ${ }^{[5]}$ Kedua pita energi ini dipisahkan oleh celah energi yang tanpa adanya elektron. Bila bahan semikonduktor menyerap foton dengan energi hf yang lebih besar dari celah energi bahan tersebut, maka sebagian elektron pindah dari pita valensi ke pita konduksi dan menghasilkan arus. ${ }^{[6,7]}$

\section{METODE}

Pengambilan data dilakukan dengan melalui proses pengamatan secara langsung dengan mengarahkan cahaya lampu pada permukaan panel surya dengan memvariasikan nilai intensitas cahaya lampu masing-masing sebesar 1230 lux, 910 lux, 810 lux, 730 lux, 633 lux dan 392 lux . lampu yang digunakan berwarna merah, kuning, hijau dan biru dengan panjang gelombang masing-masing $706 \mathrm{~nm}, 662 \mathrm{~nm}, 538 \mathrm{~nm}$ dan $496 \mathrm{~nm}$. Data yang dapat diambil yaitu tegangan pada titik kerja maksimum $\left(\mathrm{V}_{\mathrm{m}}\right)$ dan arus pada titik kerja maksimum $\left(\mathrm{I}_{\mathrm{m}}\right)$ yang dihasilkan oleh panel surya. Daya keluaran pada panel surya dapat dihitung dengan persamaan $P_{\text {out }}=V_{\mathrm{m}} \mathrm{I}_{\mathrm{m}}$. Hasil perhitungan daya keluaran panel surya ditampilkan dalam bentuk grafik panjang gelombang cahaya fungsi Pout (daya keluaran) panel surya.

\section{HASIL DAN PEMBAHASAN}

Pada penelitian ini digunakan bohlam lampu berwarna merah, kuning, hijau dan biru dengan puncak panjang gelombang masing-masing $706 \mathrm{~nm}, 662 \mathrm{~nm}, 538 \mathrm{~nm}$, dan $496 \mathrm{~nm}$. Penelitian dilakukan dengan memvariasikan intensitas cahaya yaitu 1230 lux, 910 lux, 810 lux, 730 lux, 633 lux dan 392 lux. Penentuan panjang gelombang bohlam lampu dengan menggunakan spektrofotometer Ocean Optic HR 4000 yang hasilnya ditunjukkan seperti Gambar 3.1 hingga Gambar 3.4.

Hasil tegangan keluaran (output) dan arus yang kemudian dihitung daya keluarannya sebagai fungsi panjang gelombang untuk berbagai intensitas ditunjukkan pada Gambar 3.5. Berdasarkan data yang diperoleh bahwa semua warna cahaya yang diberikan pada panel surya dapat menghasilkan arus dan tegangan keluaran. Hal ini berarti energi dari berbagai warna cahaya tersebut lebih tinggi dari energi ambang (threshold energy) atau lebih tinggi dari celah energi dari panel surya tersebut. 


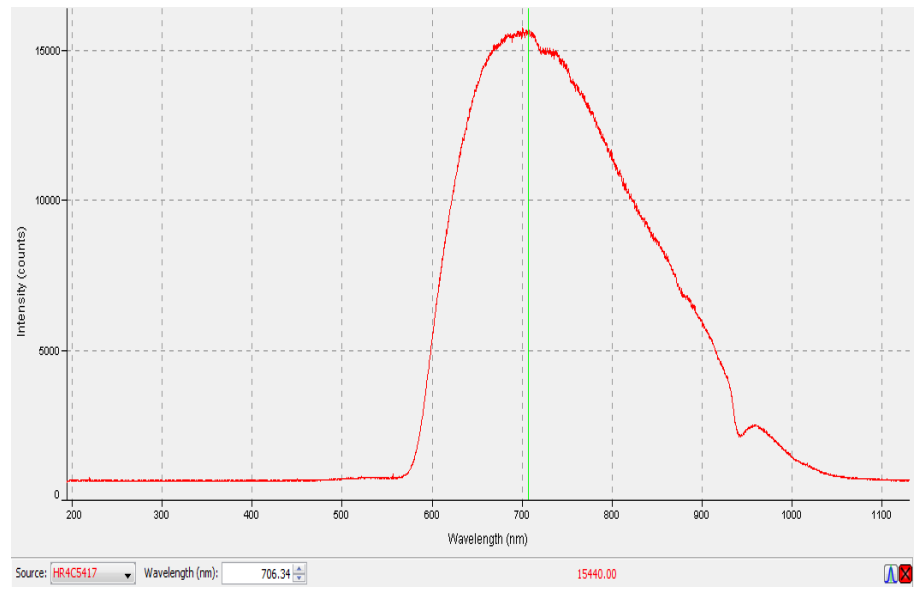

Gambar 3.1 Grafik panjang gelombang cahaya merah

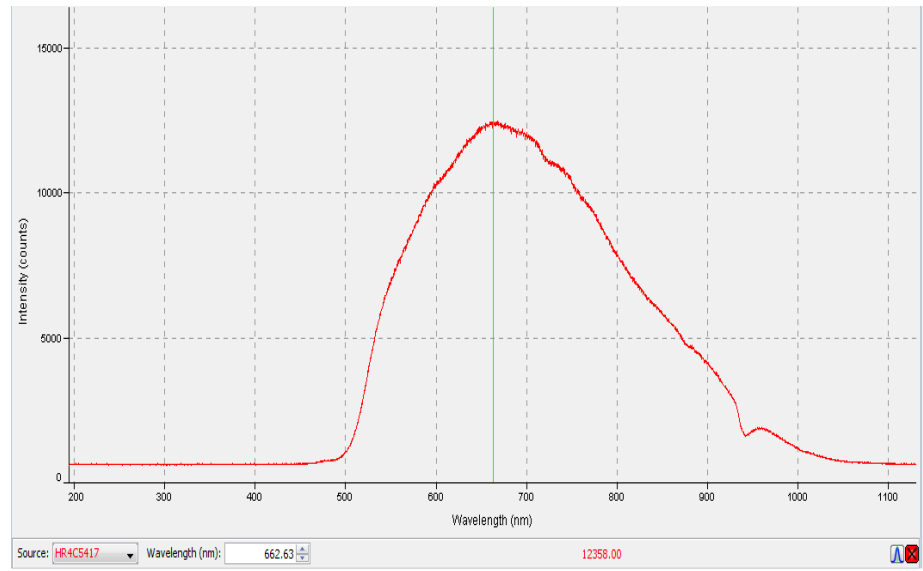

Gambar 3.2 Grafik panjang gelombang cahaya kuning

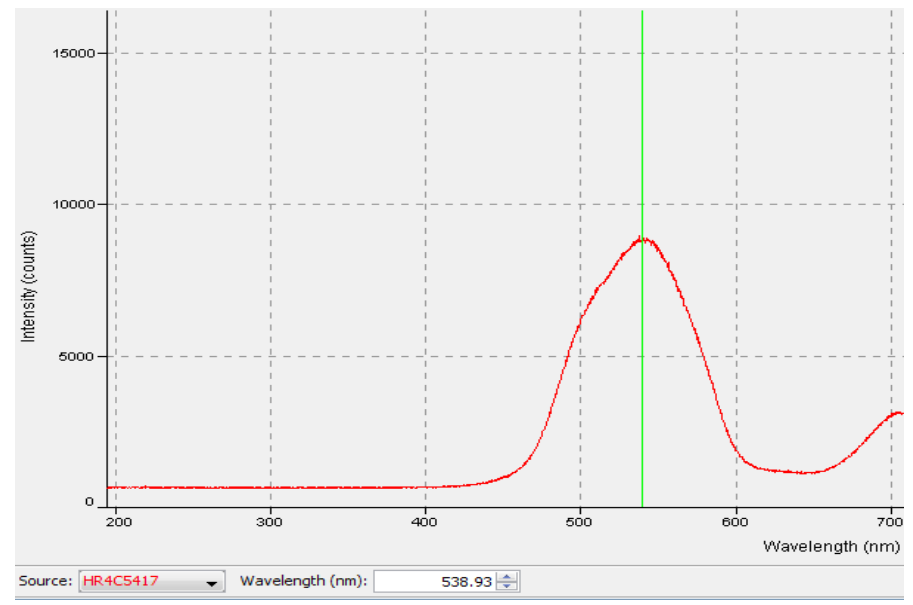

Gambar 3.3 Grafik panjang gelombang cahaya hijau 


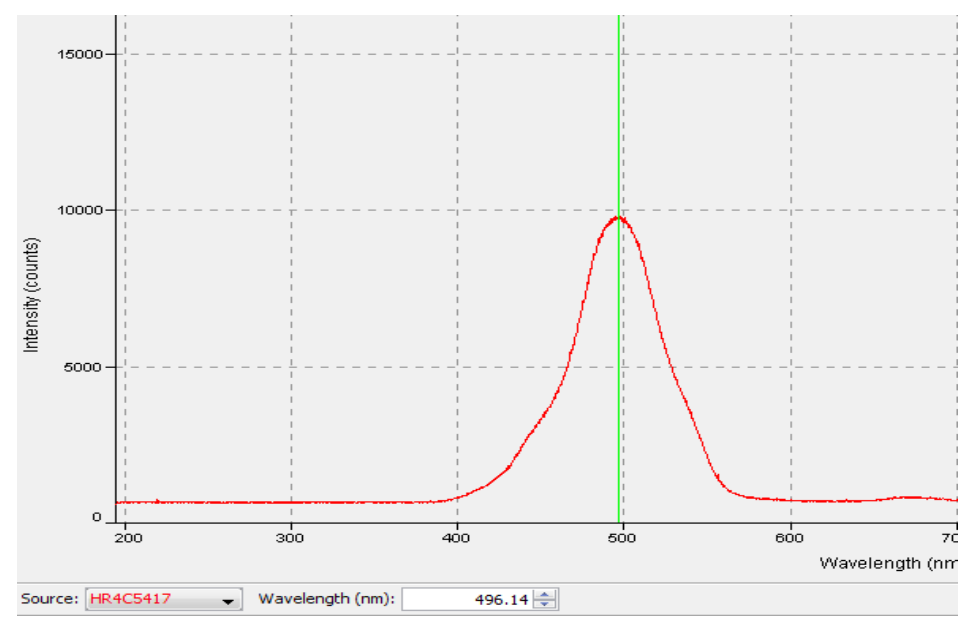

Gambar 3.4 Grafik panjang gelombang cahaya biru

Hasil juga menunjukkan bahwa intensitas cahaya yang diberikan menurun akan menghasilkan daya keluaran (output) menurun. Hal ini disebabkan karena jumlah foton cahaya berkurang dengan menurunnya intensitas cahaya. Warna merah mempunyai panjang gelombang yang lebih besar dibandingkan dengan warna kuning, hijau dan biru yang mengakibatkan warna merah menimbulkan efek panas yang lebih tinggi. Bila warna ini dipaparkan ke permukaan panel surya, maka elektron-elektron pada pita valensi akan menerima energi tambahan dari efek panas ini dan kemudian pindah ke pita konduksi yang akan menghasilkan arus. Sehingga pemaparan cahaya warna merah akan menghasilkan arus dan tegangan keluaran yang lebih besar di bandingkan warna kuning, hijau dan biru. Terlihat pada Gambar 3.5, bahwa pada intensitas 392 lux untuk semua warna menghasilkan daya keluaran yang sama. Hal ini menunjukkan bahwa panel surya mempunyai nilai energi ambang (threshold energy) di sekitar intensitas 392 lux.

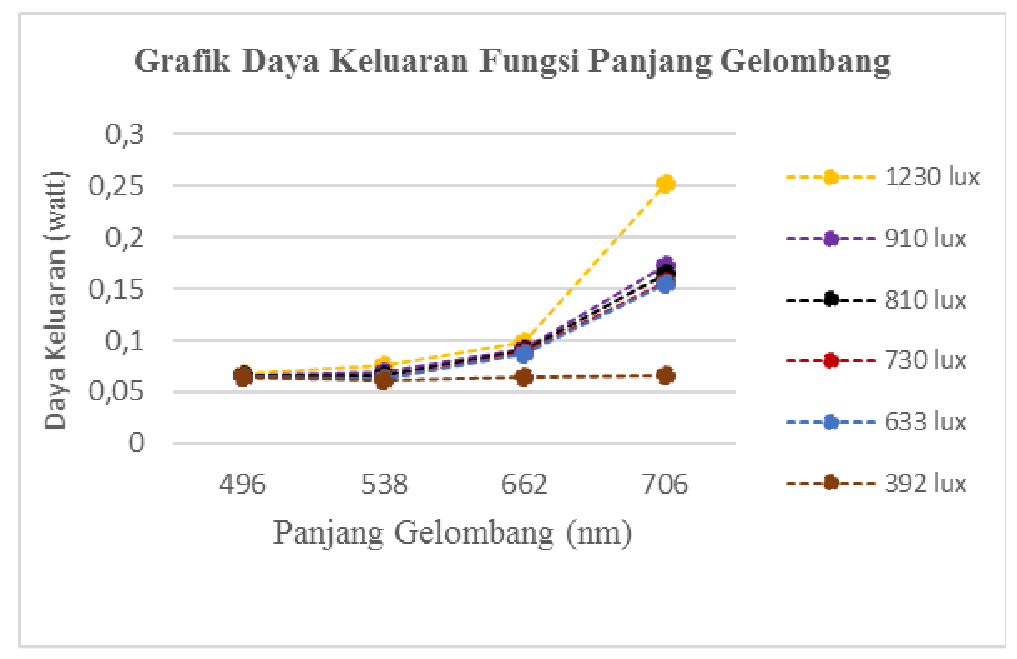

Gambar 3.5 Grafik daya keluaran fungsi panjang gelombang cahaya pada cahaya merah, kuning, hijau dan biru berbagai intensitas 


\section{SIMPULAN}

Hasil dan penelitian yang telah dilakukan, dapat disimpulkan bahwa, panjang gelombang cahaya berpengaruh terhadap daya keluaran. Semakin besar panjang gelombang maka semakin tinggi daya keluaran yang dihasilkan.

\section{DAFTAR PUSTAKA}

[1] Malvino, Prinsip-Prinsip Electronika, Erlangga, Jakarta, 2003.

[2] ABB Group, ABB QT10 Photovoltaic Plants, New York, 2017.

[3] S. Rio Reka and M. Lida, Fisika dan Teknologi Semikonduktor, Pradnya Paramita, Jakarta, 1982, pp. 55-62

[4] Kasap, S.O., Optoelectronic and photonics: Principles and Practices, United States of America, 2013.

[5] S. M. Sze and Kwok K. Ng, Physics Of Semiconductor Device, 2007, Third Edition.

[6] A.K. Ganguly, Optoelectronics Devices and Circuit: Theory and Application, Oxford: Alpha Science International, 2007, pp. 85-86.

[7] K.S. Krane, Modern Physics, Departement Of Physics Oregon State University, 2012, Third Edition.

[8] Santhiarsa, Kusuma, Kajian Energi Surya Untuk Pembangkit Tenaga Listrik, Jurnal Teknik, Vol. 4, 2005 